\title{
Using Multi-Fractal and Joint Multi-Fractal Theories to Characterise the Spatial Variability of Soil Particle Size Distribution in an Underground Coalmine Area
}

Sijia Li

China University of Geosciences Beijing

Jinman Wang ( $\nabla$ wangjinman@cugb.edu.cn )

China University of Geosciences Beijing

Jiarui Zhang

China University of Geosciences Beijing

Min Zhang

China University of Geosciences Beijing

\section{Research Article}

Keywords: Coal mining subsidence, Soil particle size distribution, Spatial variability, Multi-fractal theory, Joint multi-fractal theory

Posted Date: June 16th, 2021

DOI: https://doi.org/10.21203/rs.3.rs-478677/v1

License: (c) (i) This work is licensed under a Creative Commons Attribution 4.0 International License. Read Full License 


\section{2 characterise the spatial variability of soil particle size}

\section{3 distribution in an underground coalmine area}

Sijia Li ${ }^{\mathrm{a}}$, Jinman Wang ${ }^{\mathrm{a}, \mathrm{b},}$, Jiarui Zhang $^{\mathrm{a}}$, Min Zhang ${ }^{\mathrm{a}}$

a. School of Land Science and Technology, China University of Geosciences, 29 Xueyuan Road, Haidian District, 100083 Beijing, People’s Republic of China

b. Key Laboratory of Land Consolidation and Rehabilitation, Ministry of Natural Resources, 100035 Beijing, People's Republic of China

*Corresponding author at:

School of Land Science and Technology, China University of Geosciences, 29 Xueyuan Road, Haidian District, 100083 Beijing, People's Republic of China.

Email:wangjinman@cugb.edu.cn

Abstract: Underground coal mining leads to serious surface deformation, which negatively affects the physical properties of soils . Soil particle size distribution (PSD) is one of the most basic soil physical characteristic that influences other important properties such as soil hydraulics and thermodynamics. Understanding the spatial variability of the soil PSD in subsided land can provide targeted guidance for land reclamation. In this study, we conducted a quantitative study on the spatial variability of the soil PSD in the Pingshuo mining area on the Loess plateau, Shanxi Province in China, and explored the effects of subsidence and reclamation on the soil PSD. A plot 
experiment, including one unmined plot (UMP), one subsided plot (SUP), and one reclaimed plot (RCP), was performed in Anjialing No.3 underground coal mine in the, Pingshuo mining area. Four multi-fractal parameters of the soil PSD-D(0), $D(1)$, $\Delta \alpha(q)$, and $\Delta f(\alpha)$-were analyzed at the three sample sites. The joint multi-fractal method was carried out to analyze the spatial correlation of the soil PSD to further reveal the impacts of coal mining subsidence and land reclamation on the soil PSD.

The multi-fractal method can reflect the local non-uniformity and heterogeneity of the soil PSD, while the joint multi-fractal approach can illustrate the correlation of the soil PSD between different soil depths. The range and spatial variability of the soil PSD increased due to coal mining subsidence and the impact of subsidence on the spatial disturbance of the surface soil PSD was greater than that of the deeper layers. The spatial correlation of clay in subsided land was larger than those of unmined land and reclaimed land, whereas, for silt and sand, the correlation was smaller. Land reclamation decreased the spatial variability of the soil PSD, which was near that of the unmined land after reclamation.

Key words: Coal mining subsidence; Soil particle size distribution; Spatial variability; Multi-fractal theory; Joint multi-fractal theory.

\section{Introduction}

The coal industry, one of the most important foundations of economics, plays a key role in the national economy, which will last for a long time because of the energy structure of China (Yuan et al. 2018). China's coal resources are mainly distributed in 
ecologically vulnerable areas such as the Loess Plateau area (Wang et al. 2018c), and coal mining is dominated by underground mining (Zhang et al. 2019; Zhen et al. 2019). Open cast coal mining may result in large-scale land destruction and deformation, even soil cracks (Wang et al. 2016). On account of coal mining activities and human disturbance in the subsidence area, the soil structure has undergone fundamental changes, which in turn, exert an influence on the soil particle size distribution (PSD) and spatial variability. Only when the soil PSD, aggregate structure, water, and fertilizer retention capacity are rehabilitated can the basic conditions for vegetation and ecological restoration be provided (Wang et al. 2015a). Consequently, understanding the spatial variability of the soil PSD in the subsided area can provide effective guidance for future land reclamation work.

The spatial variability of the soil PSD is a key research field in current soil science research. The validity and potential of application of fractal theory in soil spatial variability has been verified by earlier studies (Rueth and Lennartz 2008), and it is an important tool for quantifying the spatial variability of soil properties and scale conversion (Caniego et al. 2005; Milne et al. 2013), which mainly includes single fractals (Deng et al. 2017), multi-fractals (Manuel Miras-Avalos et al. 2016), and joint multi-fractals (Biswas et al. 2012). Multi-fractals can reveal small-scale or partial features of large-scale or overall soil properties, and multi-fractal singular spectra can be obtained by calculating the fractal dimension of the different spatial regional scales of variables (Wang et al. 2018a). In general, the wider the distribution of the multi-fractal singular spectra is, the stronger the spatial variability is (Manuel 
Miras-Avalos et al. 2016). Multi-fractal parameters can better reflect the non-uniformity of the PSD compared with single fractal parameters (Guan et al. 2011; Miranda et al. 2006), with high precision and sensitivity. However, the multi-fractal method has a defect in its characterization of the soil PSD, calculating only the PSD spatial variability of the individual soil sample and, thus, not able to indicate the spatial correlation between soil properties at different layers.

The joint multi-fractal method can be conducted to explore the relationship between two variables under the same geometric conditions (Kravchenko et al. 2000). Joint multi-fractal spectrum is mostly used to analyse the correlation between two variables or between variables and their influencing factors on multiple scales (Li et al. 2011; Medina et al. 2017). For the convenience of analysis, the joint multi-fractal spectrum can be projected onto a two-dimensional plane, and the resulting greyscale maps are relatively concentrated and extended diagonally, indicating that the two variables have a higher degree of correlation; conversely, if the distribution is more discrete, the degree of correlation is lower and exhibits different distribution patterns (Biswas et al. 2012). The multi-fractal and joint multi-fractal models can be used to combine different soil variables with statistical features of different scales to obtain multiple singular spectra, which can directly reflect the spatial variability and scale characteristics of spatial sequences, revealing the spatial variation mechanism of soil characteristics more deeply (Havrylenko et al. 2016). Zeleke and Si (2006) used the above two approaches to study the multi-scale relationships between soil physical properties and various hydraulic parameters, indicating that these methods are more 
accurate than geostatistical methods.

In summary, multi-fractal and joint multi-fractal methods are suitable approaches for characterizing the spatial variability of the soil PSD; however, study on the spatial variability of soil PSD in coal mining area is still in its infancy (Manuel Miras-Avalos et al. 2016). Therefore, the objectives of our study were (i) to conduct descriptive statistical analysis of the multi-fractal parameters of soil PSD to quantify the spatial variability of soil PSD, (ii) to analyze the variation characteristics of the soil PSD between different soil layers employing the joint multi-fractal method, and (iii) to disclose the influence of coal mining subsidence and reclamation on soil PSD in coal mining subsidence areas.

\section{Materials and Methods}

\subsection{Study area}

The study area is located in the Pingshuo coal mine of Shanxi Province in China, an ecologically fragile area of the Loess Plateau. The geographical coordinates are $112^{\circ}$ $11^{\prime}$ to $113^{\circ} 30^{\prime} \mathrm{E}, 39^{\circ} 23^{\prime}$ to $39^{\circ} 37^{\prime} \mathrm{N}$ (Fig. 1). The geomorphology is mainly loess hills and mountains, and the vegetation types are mainly farmland vegetation, grassland, deciduous broad-leaved shrub and deciduous broad-leaved forest. The climate of the study area is typical of temperate arid to semi-arid continental monsoon climate. Winter is frigid with occasional rain, and summer is hot and rainy (Wang et al. 2015b). The average annual rainfall is about $450 \mathrm{~mm}$, but the annual evaporation is five times greater than the rainfall. 
The specific research location was the unmined, collapsed, and restored lands of the Anjialing No.3 underground coalmine in the Pingshuo mining area. One unmined plot, one subsided plot, and one reclaimed plot were picked to perform the research. The dimensions of each plot were $100 \mathrm{~m} \times 100 \mathrm{~m}$. There were 13 settlement cracks in the SUP, ranging in width from 0.1 to $3.5 \mathrm{~m}$. In the light of the World Reference Base for Soil Resources, the soil type was Kastanozems. The subsidence area was dominated by herbaceous plants.

The RCP and UMP were near the SUP. In June 2012, land reclamation was conducted in the RCP. After stripping off 20 centimeters of topsoil, the fissures were filled with local soils; afterwards, the collapsed land was reinforced into a horizontal terraces, and covered with the stripped topsoils. The vegetation was naturally rehabilitated in the RCP. In the RCP and UMP, the exclusive vegetation species was herbaceous plants. The terrain of the unmined and restored plots was like that of the collapsed plot. An overview of the three parcels is depicted in Fig. 2.

\subsection{Soil sampling and analysis}

In 2015, 224 soil samples were collected at 56 sampling sites at $0-20 \mathrm{~cm}, 20-40 \mathrm{~cm}$, $40-60 \mathrm{~cm}$, and $60-80 \mathrm{~cm}$ depths using a soil drill, and the sampling points were recorded by a global positioning system (GPS) receiver. A total of 16 soil profiles were excavated for each plot, and 8 additional points were placed at the subsidence cracks of the SUP (Fig. 3). The samples were transported to the laboratory, air-dried and treated with a grinding rod and sieved through a 2-mm mesh. 
The PSD of the soil samples was obtained through laser diffraction employing the Mastersizer-2000 particle size analyzer (Malvern Instruments, Malvern, England). It was operated to record the soil particle content in the 100 segments of different particle sizes obtained in the measurement interval, which are demarcated according to the US Agricultural Department (USDA) soil particle classification criteria. The soil PSD is classified by clay $(<0.002 \mathrm{~mm})$, silt $(0.002-0.05 \mathrm{~mm})$, and sand $(0.05-2$ $\mathrm{mm})$. The main soil texture in the mining area is silt loam.

\subsection{Multi-fractal analysis of the soil PSD}

The spatial variability of the soil PSD at each sampling point were discussed by multi-fractal method. The volume fraction of the soil particle size in each particle size segment in measurement interval $I=[0.02,2000]$ is obtained, and normalization is performed. After the logarithmic conversion, there are 100 equidistant dimensionless intervals in interval $J=[0,5]$. There is $N(\varepsilon)=2^{\mathrm{k}}$ subintervals in each dimensionless interval $J$, where the scale $\varepsilon=5 \times 2^{-\mathrm{k}}, k$ takes on an integer in the range of $1-6$, and there is at least one observation in each subinterval. The probability density of the soil particle size volume fraction spread in each sub-interval is $p_{\mathrm{i}}(\varepsilon)$, and by summing up the observations in all sub-intervals, $\mathrm{V}_{i}=\frac{v_{i}}{\sum_{i=1}^{100} v_{i}}, i=1,2, \ldots, 100$ can be obtained. From this, the least-squares method can be used to fit and construct a distribution function family: 
$\mu_{i}(q, \varepsilon)=\frac{p_{i}(\varepsilon)^{q}}{\sum_{i=1}^{N} p_{i}(\varepsilon)^{q}}$

153 where $\varepsilon$ is the observation scale, $\mu_{i}(q, \varepsilon)$ represents the $q^{\text {th }}$-order probability of the $i$-th

154 subinterval, $q$ ranges from $[-10,10]$, and the step size is 0.5 . The summation

$155 \sum_{i=1}^{N} p_{i}(\varepsilon)^{q}$ indicates the sum of the $q^{t h}$-order probabilities of the $N$ sub-intervals.

156 Multi-fractal generalized dimensional spectral function $D(q)$ is widely used to 157 characterize the unevenness of soil PSD.

$D(q)=\lim _{\varepsilon \rightarrow 0} \frac{1}{q-1} \frac{\lg \left[\sum_{i=1}^{N(\varepsilon)} p_{i}(\varepsilon)^{q}\right]}{\lg \varepsilon}$,

where $N(\varepsilon)$ denotes the sample size, and the scale is $\varepsilon ; p_{\mathrm{i}}(\varepsilon)$ is the sample value of the $i^{\text {th }}$ sub-interval; $q$ is the order of the $p_{\mathrm{i}}(\varepsilon)$ statistical moment, and different orders

161 indicate different scanning sparse dense regions. When $q>1$, the probability of large

162 probability subset scanning is larger, while when $q<1$, the probability of small

163 probability subset scanning is larger. When $q=0, D(0)$ is called the box-counting

164 dimension, which characterizes the range of soil PSD. When $q=1, D(1)$ is

165 information entropy, which can describe the concentration degree of soil PSD.

166 The multi-fractal singularity index of the soil PSD is

$167 \alpha(q)=\lim _{\varepsilon \rightarrow 0} \frac{\sum_{i=1}^{N(\varepsilon)} \mu_{i}(q, \varepsilon) \lg p_{i}(\varepsilon)}{\lg \varepsilon}$.

168 The multi-fractal singular spectral function of soil PSD relative to $\alpha(q)$ is

$169 f(\alpha(q))=\lim _{\varepsilon \rightarrow 0} \frac{\sum_{i=1}^{N(\varepsilon)} \mu_{i}(q, \varepsilon) \lg \mu_{i}(q, \varepsilon)}{\lg \varepsilon}$, 
where $\alpha(q)$ is the singularity index, and the function image of $f(\alpha(q)) \sim \alpha(q)$ is the multi-fractal singular spectrum. The local spatial variation of the soil particle size can be determined by the spectral width $\Delta \alpha$ of the fractal structure. The larger $\Delta \alpha$ is, the higher the heterogeneity is (Zhao et al. 2011). The parameter $\Delta f(\alpha)$ display the shape of the multi-fractal spectral attributes, and the asymmetry of soil PSD can be characterized. When $\Delta f>0$, the asymmetrical $f(\alpha)-\alpha$ spectra are shifted to the left, and when $\Delta f<0$, its shape is right deviation. Additionally, $\Delta f$ is 0 for the symmetrical spectrum. As the multifractal spectrum is shifted to the left, the effects of the high values of variables on soil PSD increase. Contrariwise, the low-value information exerts greater influence on the soil PSD. Therefore, the multi-fractal model can efficaciously characterize the heterogeneity and complexity of the spatial distribution of soil particle size (Sun et al. 2017; Du et al. 2017).

\subsection{Descriptive statistics of soil PSD}

To explore the influence of coal mining subsidence on the spatial variability of the soil PSD, the one-sample Kolmogorov-Smimov Test method was used to test the multi-fractal properties (i.e., $D(0), D(1), \Delta \alpha$, and $\Delta f$ ) of the soil PSD in different soil layers in three plots using IBM SPSS Statistics 20.0 software (Bowers et al. 2012; Zhang et al. 2015a). Moreover, the maximum, minimum, median, mean, kurtosis, skewness, and coefficient of variation $(\mathrm{CV})$ of were calculated for the multi-fractal properties of soil PSD. Kurtosis is used to measure the thickness of the data distributed at the tail, and skewness is used to measure the skew direction and extent of the distribution. The central tendency is determined by the median and mean. If 
192

193

194

$$
\alpha^{1}\left(q^{1}, q^{2}\right)=-\{\log [N(\delta)]\}^{-1} \sum_{i=1}^{N(\delta)}\left\{\mu_{i}\left(q^{1}, q^{2}, \delta\right) \log \left[p_{i}^{1}(\delta)\right]\right\}
$$

$$
\alpha^{2}\left(q^{1}, q^{2}\right)=-\{\log [N(\delta)]\}^{-1} \sum_{i=1}^{N(\delta)}\left\{\mu_{i}\left(q^{1}, q^{2}, \delta\right) \log \left[p_{i}^{2}(\delta)\right]\right\}
$$$$
211 f\left(\alpha^{1}, \alpha^{2}\right)=-\{\log [N(\delta)]\}^{-1} \sum_{i=1}^{N(\delta)}\left\{\mu_{i}\left(q^{1}, q^{2}, \delta\right) \log \left[\mu_{i}\left(q^{1}, q^{2}, \delta\right)\right]\right\},
$$ 
212 where $p_{i}^{1}(\delta)$ represents the mass probability of variable A, $p_{i}^{2}(\delta)$ represents the 213 mass probability of variable $\mathrm{B}, \alpha^{1}\left(q^{1}, q^{2}\right)$ is the singularity index of study variable A, 214 and $\alpha^{2}\left(q^{1}, q^{2}\right)$ is the singularity index of study variable B.

215 After the values of the joint multi-fractal parameters $\alpha^{1}\left(q^{1}, q^{2}\right), \alpha^{2}\left(q^{1}, q^{2}\right)$, and $f\left(\alpha^{1}, \alpha^{2}\right)$ 216 are determined, the MATLAB (MathWorks, Natick, Massachusetts) is used to 217 generate a three-dimensional spatial function image composed of $\alpha^{1}\left(q^{1}, q^{2}\right), \alpha^{2}\left(q^{1}, q^{2}\right)$, 218 and $f\left(\alpha^{1}, \alpha^{2}\right)$. Because of the diversification of the three-dimensional image in the 219 imaging angle of view, there are many inconveniences in the analysis process. It is 220 necessary to convert the three-dimensional space function image into a 221 two-dimensional plane function image, that is, the image is projected to $\alpha^{1}\left(q^{1}, q^{2}\right)$ and $222 \alpha^{2}\left(q^{1}, q^{2}\right)$. On the plane of the composition, a two-dimensional greyscale image of the 223 joint multi-fractal spectral can be obtained to identify the spatial variability features 224 and their mutual relations in the fractal structure. From the concentration or dispersion 225 degree of the greyscale image, the correlation between the two research objects can be 226 judged. If the two-dimensional greyscale image exhibits a relatively concentrated 227 distribution, this indicates that the correlation between the research objects is strong. 228 The spatial distribution of variables has a certain degree of synergy. If the two-dimensional greyscale shows a relatively discrete distribution, this indicates that

230 the correlation between the two research variables is relatively low, and the spatial 231 distribution law is relatively independent. The difference between the layers is large. 232 Based on the results of soil classification, the joint multi-fractal analysis was conducted to analyze the soil texture of the adjacent soil layers at $0-80 \mathrm{~cm}$ depth (two 
234 adjacent soil depths were compared with each other). Three-dimensional joint 235 multi-fractal spectra and projected 2D greyscale images are obtained.

\section{$236 \quad 3$ Results}

\subsection{Descriptive statistics analysis of the soil PSD}

238 The descriptive statistical characteristics of the clay content, silt content, and sand

239 content of different soil layers in three sampling plots are shown in Tables 1-3.

\subsubsection{Clay content}

The clay contents of the UMP, SUP, and RCP were $11.82 \%-22.30 \%, 4.39 \%-24.04 \%$ and $10.05 \%-25.56 \%$, respectively, and the coefficients of variation were $12.36 \%-16.37 \%, 21.00 \%-34.34 \%$ and $15.08 \%-19.5 \%$, showing moderate variation.

The clay content in the SUP decreased, while the CV increased. The overall clay

245 content in the three samples was expressed as UMP $>$ RCP $>$ SUP, indicating that land

246 subsidence decreased the clay content, and land reclamation increased the clay 247 content.

\subsubsection{Silt content}

249 The silt contents in the UMP, SUP, and RCP were $40.35 \%-60.16 \%, 36.38 \%-63.45 \%$, 250 and $39.55 \%-60.45 \%$, respectively; and the coefficients of variation were $2517.62 \%-10.56 \%, 6.77 \%-10.36 \%$ and $6.17 \%-8.25 \%$, showing weak variation. All three

252 plots belong to silty clay loam according to the mean values, and the silt contents in 253 the three plots are near each other. The coefficient of variation of the SUP is slightly 254 larger than those of the other two plots. Compared to the clay content and sand 
content, the influence of coal mining subsidence and land restoration on the soil silt content are relatively low.

\subsubsection{Sand content}

The sand contents of the UMP, SUP, and RCP were $25.66 \%-39.79 \%, 31.57 \%-47.45 \%$, and $24.44 \%-39.95 \%$, respectively, and the coefficients of variation were 9.96\%-15.47\%, 7.23\%-9.62\%, and 6.57\%-9.28\%, showing weak variation. The sand content of the SUP showed a marked rise. The CV of the three plots in the same soil layer showed that UMP $>$ SUP $>$ RCP, and land subsidence and land reclamation decreased the variation in the sand content.

\subsection{Multi-fractal characteristics of the soil PSD}

Table 4, 5, 6 and 7 respectively shows the the multifractal parameters description of the statistical eigenvalues of the three sampling plots. All the K-S test $p$ values were greater than 0.05 , and the sample values followed the normal distribution (Hu et al. 2018). The median and mean values of the soil multi-fractal parameters $D(0), D(1)$, $\Delta \alpha(q)$, and $\Delta f(\alpha)$ were very close in the three plots, indicating that the distribution of sample data was highly concentrated.

\section{$3.2 .1 \mathrm{D}(0)$}

The multi-fractal parameter $D(0)$ values of the UMP, SUP, and RCP were $0.8178-0.9501,0.8178-0.9406$, and $0.8178-0.9501$, respectively. Overall, when the $q$ values are equal, the $D(0)$ of the SUP was greater than those of the UMP and RCP. The multi-fractal parameter $D(0)$ has a small $\mathrm{CV}$ value $(1.27 \%-5.02 \%)$, which falls in the weak variation category. The CV value of the SUP is the smallest, and the CV 
values of the RCP and UMP soil layers are near each other, indicating that the severe coal mining subsidence has multi-fractal characteristics. Land subsidence was shown to influence the degree of spatial variability of $D(0)$; however, the effect was relatively low. After land reclamation, the soil PSD range can reach a level similar to that of the unmined plot.

\subsubsection{D(1)}

The multi-fractal parameter $D(1)$ values of the UMP, SUP, and RCP were $0.7165-0.8710,0.6967-0.8712$, and $0.7285-0.8953$, respectively. The distribution law of multi-fractal parameter $D(1)$ had certain similarities with $D(0)$. When the step size $q$ is equal, the $D(1)$ of the SUP was larger than that of the UMP or RCP. Coal mining subsidence increased the concentration level of the soil PSD. The change in the CV values of $D(1)$ of the three plots was consistent with that of the parameter $D(0)$. Compared to $D(0)$, the $\mathrm{CV}$ values of $D(1)$ for each plot were slightly larger than that of $D(0)$. However, they were still within the weak variation range (2.40\%-6.02\%).

\section{$3.2 .3 \Delta \alpha$}

The multi-fractal parameter $\Delta \alpha$ values of UMP, SUP, and RCP were $0.8786-1.0012$, $0.8073-1.0614$, and $0.8569-1.0033$, respectively. The parameter $\Delta \alpha$ of the UMP exhibited a gradual decrease with the increase in the soil depth. Mining activities presented an artificial disturbance to the soil profile, and $\Delta \alpha$ exhibited fluctuations. After land reclamation, the spatial variability of the surface soil layer was close to that of the unmined land, and there remained fluctuations in the deep soil depths. Land subsidence caused an increase in the spatial variability of the local heterogeneity of 
the soil PSD, and land reclamation decreased the variability. However, the difference in the CV values of parameter $\Delta \alpha$ among the various plots was relatively small (2.55\%-6.87\%). The CV values in the deeper soil was higher than those in the topsoil in each plot, except at the depth of $20-40 \mathrm{~cm}$ in the SUP.

\section{$3.2 .4 \Delta f$}

The multi-fractal parameter $\Delta f$ values of the UMP, SUP, and RCP were between $0.0235-0.4680,0.0318-0.5259$, and 0.0531-0.4940, respectively. Land subsidence slightly increased the asymmetry of the soil PSD. All of the CV values of the different soil depths in the three plots were within the range of moderate variation (21.95\%-55.79\%), and the difference in the CV values of the parameter $\Delta f$ among the various plots was relatively small.

\subsection{Joint multi-fractal analysis of soil PSD}

The joint multi-fractal results of the soil PSD at the three sample sites are shown in Figs. 4-12. These figures intuitively present the variability and spatial correlation of soil PSD between different soil depths.

\subsubsection{Clay content}

The joint multi-fractal spectra and projection greyscale maps of the PSD multi-fractal parameters of the clay soils in the three sample sites are reflected in Figs. 4, 5, and 6.

The concentration degree of dots in the clay content grey map in the UMP was the highest, and the greyscale dispersion of the UMP in $0-20 \mathrm{~cm}$ and $20-40 \mathrm{~cm}$ topsoil was higher than that of the SUP or RCP. The SUP had a relatively weak concentration of clay content, and the distribution was more discrete. The degree of joint greyscale 
concentration in the RCP soil layers was between that of the UMP and SUP, with higher joint gray scale concentrations in $20-40 \mathrm{~cm}$ and $40-60 \mathrm{~cm}$ soils. Under natural conditions, the degree of correlation between the clay content of each soil layer was relatively high, and land subsidence decreased this spatial correlation while land reclamation increased the spatial correlation.

\subsubsection{Silt content}

The joint multi-fractal spectra and projection greyscale maps of the PSD multi-fractal parameters of the silt soils in the three sample sites are shown in Figs. 7, 8, and 9. There was a certain similarity between the silt content and the clay content in the joint multi-fractal greyscale pattern. The concentration of dots in the greyscale of the UMP silt content was relatively high, and the degree of correlation between the middle soil layers was greater than those of the upper and bottom soil layers. The concentration degree of the grey map of the SUP increasingly grew with the improve of soil depth, but was smaller than that of the UMP or RCP, indicating that land subsidence reduced the correlation between the surface soils. The concentration of dots in the joint greyscale map between the soil layers of the RCP was relatively high, and was opposite to the changing trend in the concentration degree of the UMP with the increase of soil depth. The concentration degree firstly decreased and then increased. As a whole, the concentration degree of the greyscale maps of the silt content was $\mathrm{UMP}>\mathrm{RCP}>\mathrm{SUP}$.

\subsubsection{Sand content}

The joint multi-fractal results of sand soil PSD are presented Figs. 10, 11, and 12. 
The distribution patterns of the joint multi-fractal greyscale image of sand content was different compared to those of the clay and silt content. The correlation degree of sand content of SUP was high, there was no clear law between the different soil layers, the concentration degree of the greyscale of sand contents was greater than that of clay or silt content. The UMP and RCP exhibited the similar multi-fractal greyscale results. In UMP and RCP, the joint multi-fractal parameters of the soil layers of $0-20 \mathrm{~cm}$ and $20-40 \mathrm{~cm}$, and the soil layers of 40-60 $\mathrm{cm}$ and $60-80 \mathrm{~cm}$ were all distributed in a small range, while the distribution range of the joint multi-fractal parameters of the 20-40 $\mathrm{cm}$ and 40-60 $\mathrm{cm}$ soil layers were relatively large. The concentration degrees of the UMP and RCP were less than those of the SUP, and they were less than those of clay or silt in the horizontal direction. The concentration degree of sand content was characterized by SUP $>$ UMP $>$ RCP, indicating that land subsidence resulted in a great effect on the soil PSD of sand, leading to an increase in the correlation of the soil PSD between different depths.

\section{Discussion}

\subsection{Impacts of coal mining subsidence on the spatial variability of the soil PSD}

Analysis of the spatial variability of the distribution of the joint multi-fractal attributes, the mechanism of the impact of land subsidence on the soil PSD may be revealed. The spatial correlation of the soil PSD can be significantly affected by subsidence (Wang et al. 2018b; Xiao et al. 2013). In this study, the spatial correlation of the clay and silt content was relatively high under natural conditions, while its counterpart in the 
subsidence area was clearly reduced. Under natural conditions, the spatial correlation of the soil sand content was relatively low, but land subsidence caused the spatial correlation to increase.

Moreover, it was manifested that land subsidence resulted in an increase in the spatial variability of the soil PSD range, concentration, heterogeneity, and asymmetry. Compared to the unmined soil with the same site conditions in the study area, the subsidence resulting from coal mining can give rise to serious surface deformation and soil destruction, which, consequently, change soil physical properties, such as particle size, bulk density, and porosity (Wang et al. 2017a). Therefore, soil erosion in the subsidence area was intensified (Zhang et al. 2011). Soil erosion could give rise to the breakage of some coarse particles and the deprivation of some fine particles (Jing et al. 2018), changing the soil PSD (Liu et al. 2009; Zhang et al. 2010). Land subsidence would lead to an increase in the range of the soil PSD, and undermine the spatial auto-correlation of the soil PSD, causing the PSD to be in a disordered uneven state (Zhang et al. 2015b). This change was also confirmed by the reduction in the clay content and the increase in the sand content in the subsidence area in this study. As a consequence, land subsidence increased the spatial variability of the soil PSD range $(D(0))$, concentration $(D(1))$, heterogeneity $(\Delta \alpha)$, and asymmetry $(\Delta f)$.

\subsection{Impacts of land reclamation on the spatial variability of the soil PSD}

It was shown that the soil PSD and its spatial correlation between the soil depths after land reclamation was close to those of unmined soils. In the RCP, the implementation of land reclamation began in 2012. Soil restoration improved soil physical properties 
(Biswas 2019; Nyamadzawo et al. 2008; Wang et al. 2008). The variability of the soil PSD of the RCP approximates that of the UMP, through surface crack filling and vegetation reconstruction. With increasing soil depth, the difference in the distribution between the layers is reduced. Soil remediation may weaken the variability of the soil physical attributes (Wang et al. 2015a; Wang et al. 2017b). In addition, land reclamation exhibited a greater impact on the soil PSD at the $0-20 \mathrm{~cm}$ depth than that at other soil layers, which also demonstrated the impact of land reclamation measures on PSD in the RCP soils (Zhou et al. 2015). Therefore, land reclamation decreased the spatial variability of the soil PSD range $(D(0))$, concentration $(D(1))$, heterogeneity $(\Delta \alpha)$, and asymmetry $(\Delta f)$.

Affected by factors such as reclamation method, reclamation time, and surface crack filling source, the soil PSD of different soil layers was inconsistent with that of the unmined soil, indicating that the reclamation activity exerts a great impact on the vertical distribution of the soil PSD (Wang et al. 2013). Land reclamation is an artificial activity. Although it can guarantee an approximate range of soil particle size to a certain extent, soils are mechanically compacted during the process because of the use of large machinery (Wang et al. 2012). Therefore, land reclamation technologies should be improved to reduce the influence of machinery compaction on soil physical characteristics (Adeli et al. 2019). Considering the ecological restoration of the mining area, the optimal time for reclamation in the subsided land should receive consideration (Huang et al. 2018). 
408 In this study, the spatial variability of the soil particle size distribution in an

409 underground coalmine area was investigated using multi-fractal and joint multi-fractal

410 methods, and the impacts of coal mining subsidence and land rehabiliation on the soil

411 PSD were discussed. Multi-fractal parameters $(D(0), D(1), \Delta \alpha(q)$, and $\Delta f(\alpha))$ can

412 reflect the spatial variability of different soil particle sizes from different aspects and

413 scales. The overall variability of the soil PSD can be characterized by the statistical

414 analysis of multi-fractal attributes, and the joint multi-fractal model can achieve

415 quantitative characterization of the soil PSD between different depths. Land

416 subsidence increased the spatial variability of the soil PSD, as well as the spatial

417 variability of the soil PSD range, concentration, heterogeneity, and asymmetry.

418 Meanwhile, land reclamation decreased the spatial variability of the soil PSD. In

419 summary, coal mining subsidence and land reclamation changed the spatial

420 correlation of the soil PSD between different depths.

422 Acknowledgments

423 This research was supported by the National Key Research and Development 424 Program of China (2017YFF0206802) and the National Natural Science Foundation 425 of China (41877532).

\section{References:}


Adeli A, Brooks J P, Read J J, McGrew R. Jenkins J N (2019) Post-reclamation Age Effects on Soil Physical Properties and Microbial Activity Under Forest and Pasture Ecosystems. Communications in Soil Science and Plant Analysis 50(1): 20-34.

Aghasi B, Jalalian A, Khademi H, Toomanian N (2017) Sub-basin scale spatial variability of soil properties in Central Iran. Arabian Journal of Geosciences 10(6): 136-156.

Biswas A (2019) Joint multifractal analysis for three variables: Characterizing the effect of topography and soil texture on soil water storage. Geoderma 334: 15-23.

Biswas A, Zeleke T B, Si B C (2012) Multifractal detrended fluctuation analysis in examining scaling properties of the spatial patterns of soil water storage. Nonlinear Processes in Geophysics 19(2): 227-238.

Bowers M C, Tung W W, Gao J B (2012) On the distributions of seasonal river flows: Lognormal or power law? Water Resources Research 48(5): 5536-5547.

Caniego F J, Espejo R, Martin M A, San Jose F (2005) Multifractal scaling of soil spatial variability. Ecological Modelling 182(3-4): 291-303.

Deng Y, Cai C, Xia D, Ding S, Chen J (2017) Fractal features of soil particle size distribution under different land-use patterns in the alluvial fans of collapsing gullies in the hilly granitic region of southern China. Plos One 12(3): 555-575.

Du Y C, Han J C, Zhang S W, Huang Y F, Wang H Y, Luo L T (2017) Multidimensional analysis of particle size fractal characteristics in a farmland soil profile. In: K.L. Huang, K.W. Kim and J. Liu (Editors), International Conference on Energy Engineering and Environmental Protection. IOP Conference Series-Earth and Environmental Science 52: 12053-12063.

Guan X, Yang P, Lv Y (2011) Analysis on Spatial Variability of Soil Properties Based on Multifractal Theory. Journal of Basic Science and Engineering 19(5): 712-720.

Havrylenko S B, Bodoque J M, Srinivasan R, Zucarelli G V, Mercuri P (2016) Assessment of the soil water content in the Pampas region using SWAT. Catena 137: 298-309.

Hu W, Shao M A, Wang Q J, Reichardt K (2008) Soil water content temporal-spatial variability of the surface layer of a Loess Plateau hillside in China. Scientia Agricola 65(3): 277-289.

Hu Z, Wang C, Li K, Zhu X (2018) Distribution characteristics and pollution assessment of soil heavy metals over a typical nonferrous metal mine area in Chifeng, Inner Mongolia, China. Environmental Earth Sciences 77(18): 638-657.

Huang Y, Kuang X, Cao Y, Bai Z (2018) The soil chemical properties of reclaimed land in an arid grassland dump in an opencast mining area in China. Rsc Advances 8(72): 41499-41508.

Jing Z, Wang J, Zhu Y, Feng Y (2018) Effects of land subsidence resulted from coal mining on soil nutrient distributions in a loess area of China. Journal of Cleaner Production 177: 350-361.

Kravchenko A N, Bullock, D G, Boast C W (2000) Joint multifractal analysis of crop yield and terrain slope. Agronomy Journal 92(6): 1279-1290.

Li Y, Li M, Horton R (2011) Single and Joint Multifractal Analysis of Soil Particle Size Distributions. Pedosphere 21(1): 75-83.

Liu X, Zhang G, Heathman G C, Wang Y, Huang C (2009) Fractal features of soil particle-size distribution as affected by plant communities in the forested region of Mountain Yimeng, China. Geoderma 154(1-2): 123-130.

Manuel Miras-Avalos J, Trigo-Cordoba E, da Silva-Dias R, Varela-Vila I, Garcia-Tomillo A (2016) Multifractal behaviour of the soil water content of a vineyard in northwest Spain during two growing seasons. Nonlinear Processes in Geophysics 23(4): 205-213. 
Medina H, van Lier Q, Garcia J, Elena Ruiz M (2017) Regional-scale variability of soil properties in Western Cuba. Soil \& Tillage Research 166: 84-99.

Meng H, Zhu Y, Evans G J, Yao X (2015) An approach to investigate new particle formation in the vertical direction on the basis of high time-resolution measurements at ground level and sea level. Atmospheric Environment 102: 366-375.

Milne A E, Haskard K A, Webster C P, Truan I A, Lark R M (2013) Wavelet Analysis of the Variability of Nitrous Oxide Emissions from Soil at Decameter to Kilometer Scales. Journal of Environmental Quality 42(4): 1070-1079.

Miranda J G, Montero E, Alves M C, Gonzalez A P, Vazquez E V (2006) Multifractal characterization of saprolite particle-size distributions after topsoil removal. Geoderma 134(3-4): 373-385.

Nyamadzawo G, Shukla M K, Lal R (2008) Spatial variability of total soil carbon and nitrogen stocks for some reclaimed minesoils of Southeastern Ohio. Land Degradation \& Development 19(3): 275-288.

Rueth B, Lennartz B (2008) Spatial variability of soil properties and rice yield along two catenas in southeast China. Pedosphere 18(4): 409-420.

Sun C, Liu G, Xue S (2017) Response of soil multifractal characteristics and erodibility to 15-year fertilization on cropland in the Loess Plateau, China. Archives of Agronomy and Soil Science 63(7): 956-968.

Ussiri D A, Lal R, Jacinthe P A (2006) Soil properties and carbon sequestration of afforested pastures in reclaimed minesoils of Ohio. Soil Science Society of America Journal 70(5): 1797-1806.

Wang D, Fu B, Zhao W, Hu H, Wang Y (2008) Multifractal characteristics of soil particle size distribution under different land-use types on the Loess Plateau, China. Catena 72(1): 29-36.

Wang J, Guo L, Bai Z, Yang L (2016) Using computed tomography (CT) images and multi-fractal theory to quantify the pore distribution of reconstructed soils during ecological restoration in opencast coal-mine. Ecological Engineering 92: 148-157.

Wang J, Guo L, Bai Z, Yang R, Zhang M (2013) Succession law of reclaimed soil and vegetation on opencast coal mine dump of loess area. Transactions of the Chinese Society of Agricultural Engineering 29(21): 223-232.

Wang J, Lu X, Feng Y, Yang R (2018a) Integrating multi-fractal theory and geo-statistics method to characterize the spatial variability of particle size distribution of minesoils. Geoderma 317: $39-46$.

Wang J, Qin Q, Bai Z (2018b) Characterizing the effects of opencast coal-mining and land reclamation on soil macropore distribution characteristics using 3D CT scanning. Catena 171: 212-221.

Wang J, Qin Q, Guo L, Feng Y (2018c) Multi-fractal characteristics of three-dimensional distribution of reconstructed soil pores at opencast coal-mine dump based on high-precision CT scanning. Soil \& Tillage Research 182: 144-152.

Wang J, Wang P, Qin Q, Wang H (2017a) The effects of land subsidence and rehabilitation on soil hydraulic properties in a mining area in the Loess Plateau of China. Catena 159: 51-59.

Wang J, Yang R, Bai Z (2012) Succession law and model of reclaimed soil quality of opencast coal mine dump in grassland. Transactions of the Chinese Society of Agricultural Engineering 28(14): 229-235.

Wang J, Yang R, Bai Z (2015a) Spatial variability and sampling optimization of soil organic carbon and total nitrogen for Minesoils of the Loess Plateau using geostatistics. Ecological Engineering 82: $159-164$. 
Wang J, Yang R, Feng Y (2017b) Spatial variability of reconstructed soil properties and the optimization of sampling number for reclaimed land monitoring in an opencast coal mine. Arabian Journal of Geosciences 10(2): 46-58.

Wang J, Zhang M, Bai Z, Guo L (2015b) Multi-fractal characteristics of the particle distribution of reconstructed soils and the relationship between soil properties and multi-fractal parameters in an opencast coal-mine dump in a loess area. Environmental Earth Sciences 73(8): 4749-4762.

Xiao W, Hu Z, Zhang R, Zhao Y (2013) A simulation of mining subsidence and its impacts to land in high ground water area- An integrated approach based on subsidence prediction and GIS. Disaster Advances 6: 142-148.

Yuan Y, Zhao Z, Niu S, Xue Z, Wang Y, Bai Z (2018) Reclamation promotes the succession of the soil and vegetation in opencast coal mine: A case study from Robinia pseudoacacia reclaimed forests, Pingshuo mine, China. Catena 165: 72-79.

Zeleke T B, Si B C (2006) Characterizing scale-dependent spatial relationships between soil properties using multifractal techniques. Geoderma 134(3-4): 440-452.

Zhang C, Chen X, Quan X, Dong Y, Wei J (2015a) Characteristics of Soil Particle Size in the Urumqi City. Research of Soil and Water Conservation 22(2): 213-218.

Zhang J, Zhang Q, Yang Z, Chen M, Li Y, Chen D (2010) Spatial Variability of Topsoil Organic Matter and Total Nitrogen in Linfen Basin, Shanxi and Its Influencing Factors. Journal of Soil Science 41(4): 839-844.

Zhang L, Wang J, Bai Z, Lv C (2015b) Effects of vegetation on runoff and soil erosion on reclaimed land in an opencast coal-mine dump in a loess area. Catena 128: 44-53.

Zhang Y, Jiang D, Shi D, Jiang G, Cheng Z (2011) Research on Soil Erosion Characteristics and Soil and Water Conservation Pattern in Coal Mine Exploration Area of Chongqing. Research of Soil and Water Conservation 18(6): 94-99.

Zhang Z, Wang J, Li B (2019) Determining the influence factors of soil organic carbon stock in opencast coal-mine dumps based on complex network theory. Catena 173: 433-444.

Zhao P, Shao M, Wang T J (2011) Multifractal analysais of particle-size distributions of alluvial soils in the dam farmland on the Loess Plateau of China. African Journal of Agricultural Research 6(18): 4177-4184.

Zhen Q, Zheng J, Zhang X, Shao M (2019) Changes of solute transport characteristics in soil profile after mining at an opencast coal mine site on the Loess Plateau, China. The Science of the total environment 665: 142-152.

Zhou D, Wu K, Cheng G, Li L (2015) Mechanism of mining subsidence in coal mining area with thick alluvium soil in China. Arabian Journal of Geosciences 8(4): 1855-1867. 


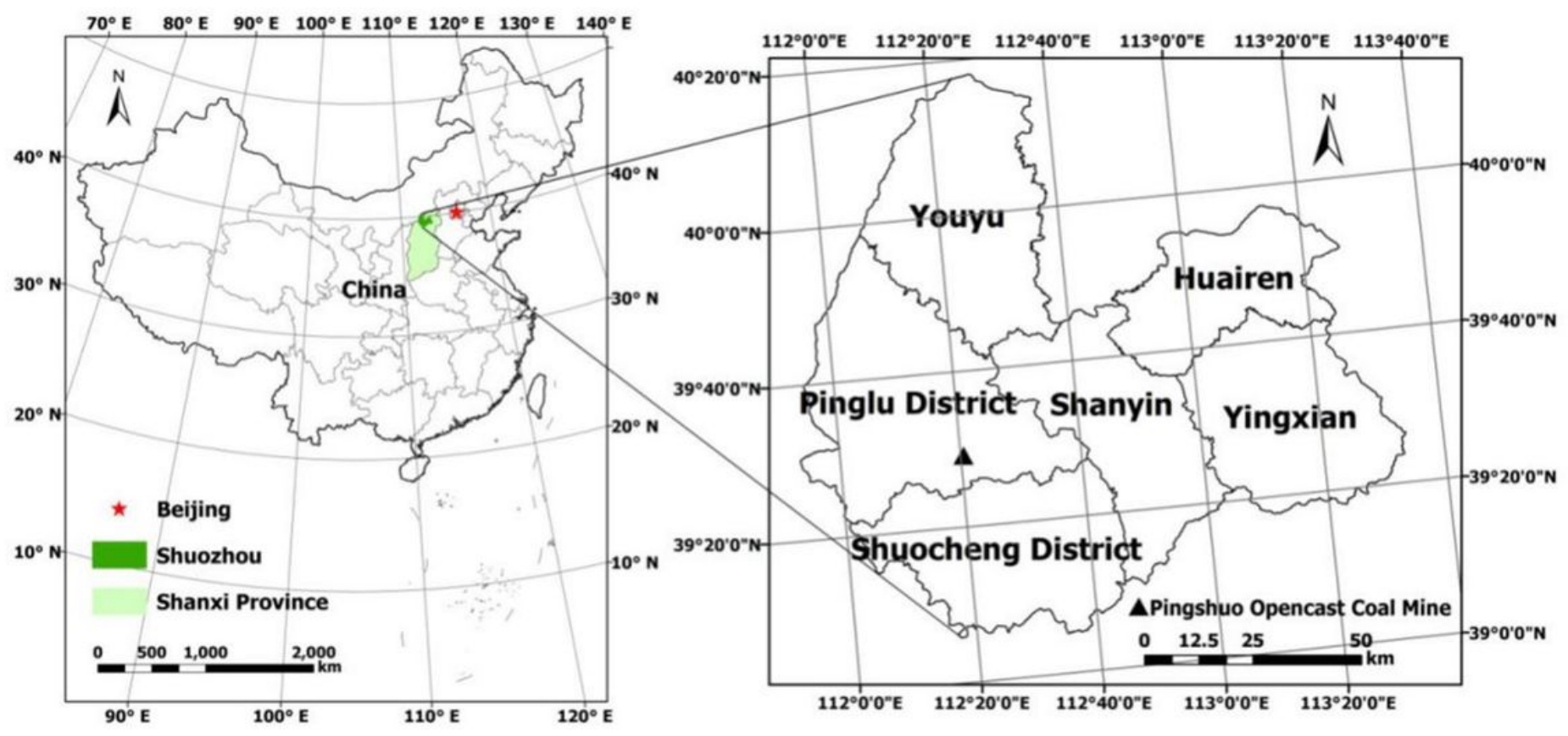

\section{Figure 1}

Schematic diagram of the location of Pingshuo mining area. Note: The designations employed and the presentation of the material on this map do not imply the expression of any opinion whatsoever on the part of Research Square concerning the legal status of any country, territory, city or area or of its authorities, or concerning the delimitation of its frontiers or boundaries. This map has been provided by the authors. 


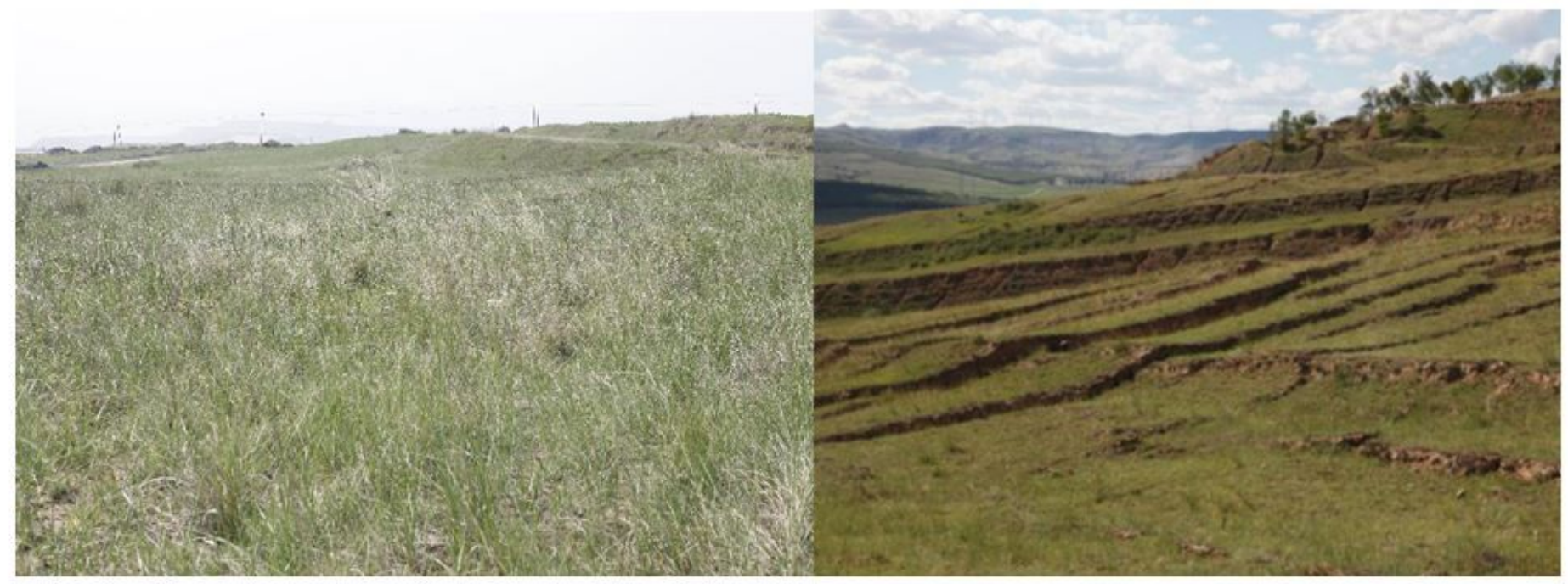

a

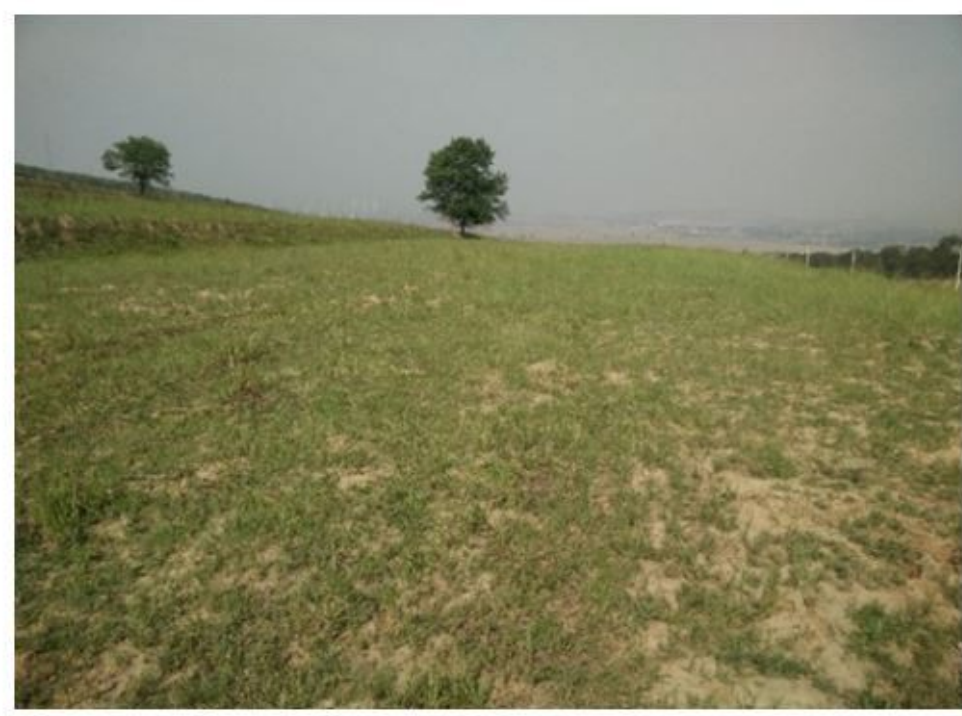

c

Figure 2

Overview of study plots (a. UMP, b. SUP and c. RCP). 
背

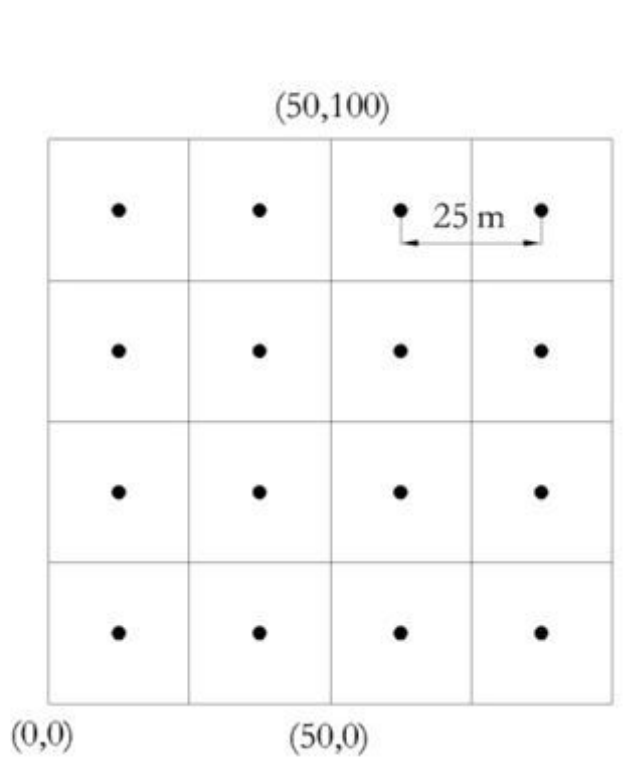

a.UMP
北

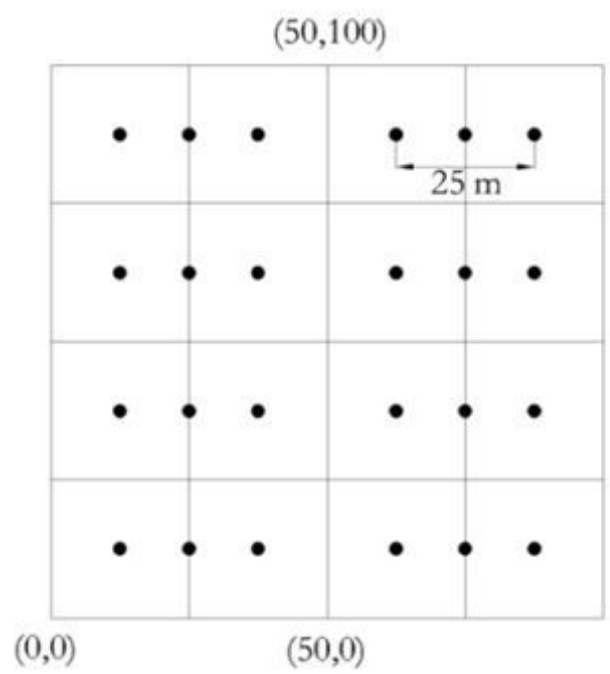

b.SUP

北

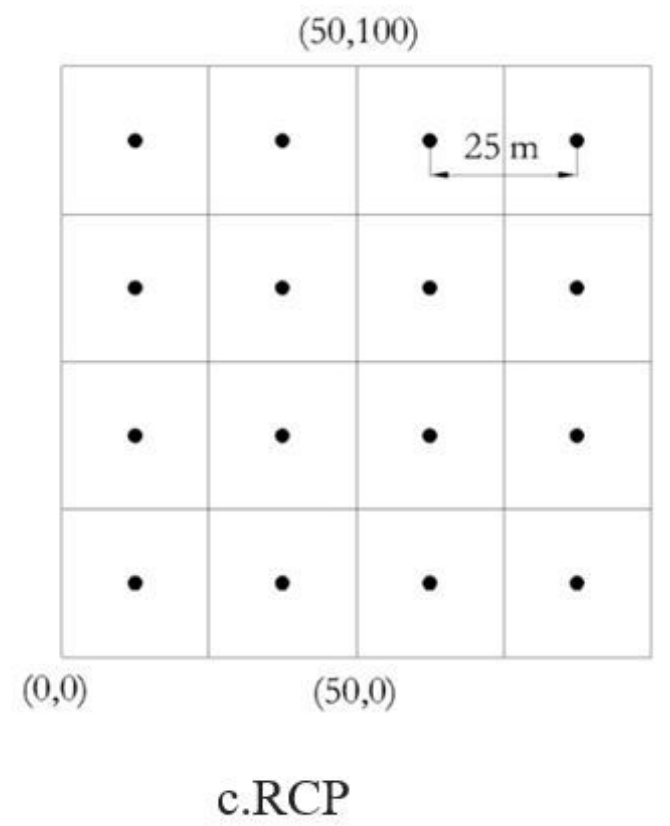

Figure 3

Sampling point layout in study area 


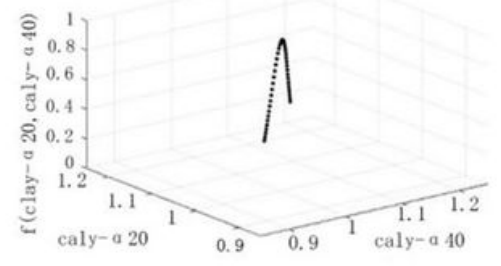

$0-20 \mathrm{~cm}$ and $20-40 \mathrm{~cm}$

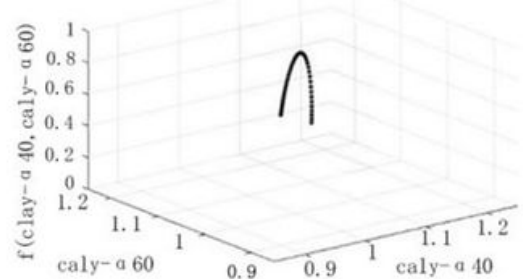

$20-40 \mathrm{~cm}$ and $40-60 \mathrm{~cm}$

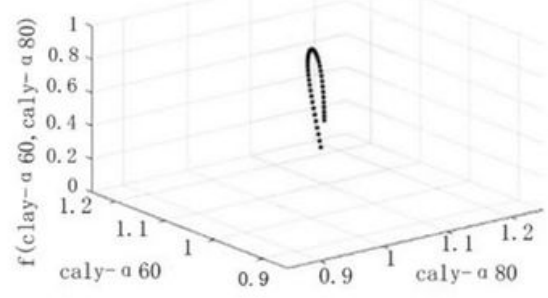

$40-60 \mathrm{~cm}$ and $60-80 \mathrm{~cm}$

a. Joint multi-fractal spectra of clay content

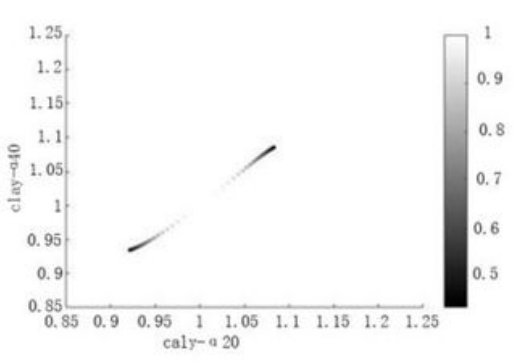

$0-20 \mathrm{~cm}$ and $20-40 \mathrm{~cm}$

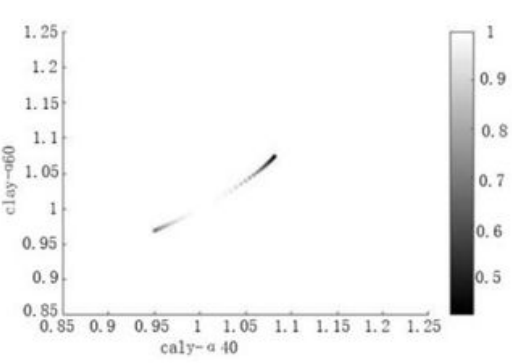

$20-40 \mathrm{~cm}$ and $40-60 \mathrm{~cm}$

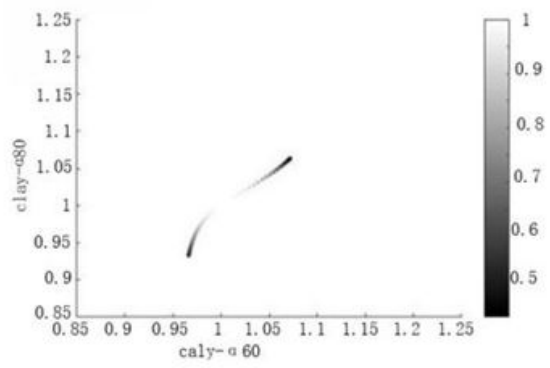

$40-60 \mathrm{~cm}$ and $60-80 \mathrm{~cm}$

b.Joint multi-fractal spectrum projection grayscale of clay content

\section{Figure 4}

Joint multi-fractal spectra and projection grayscale of clay content in UMP. 


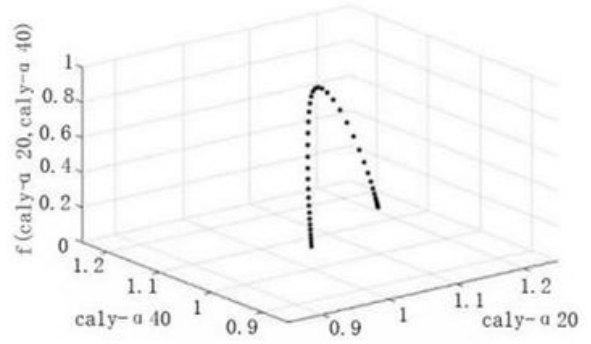

$0-20 \mathrm{~cm}$ and $20-40 \mathrm{~cm}$

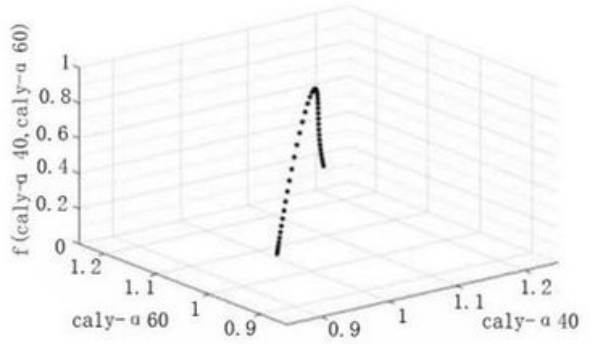

$20-40 \mathrm{~cm}$ and $40-60 \mathrm{~cm}$

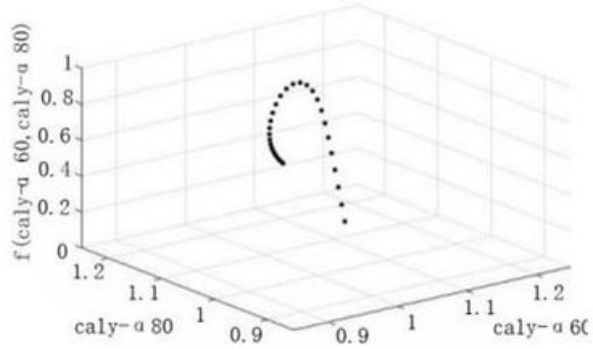

$40-60 \mathrm{~cm}$ and $60-80 \mathrm{~cm}$

a. Joint multi-fractal spectra of clay content

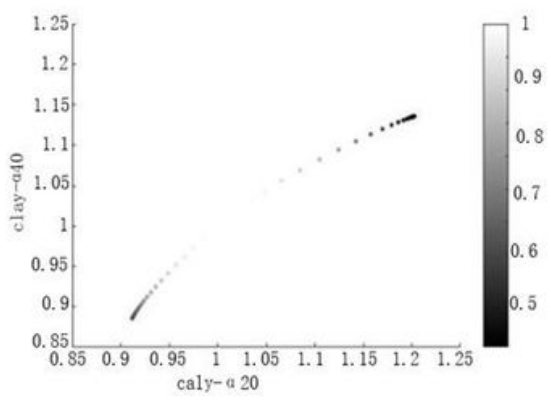

$0-20 \mathrm{~cm}$ and $20-40 \mathrm{~cm}$

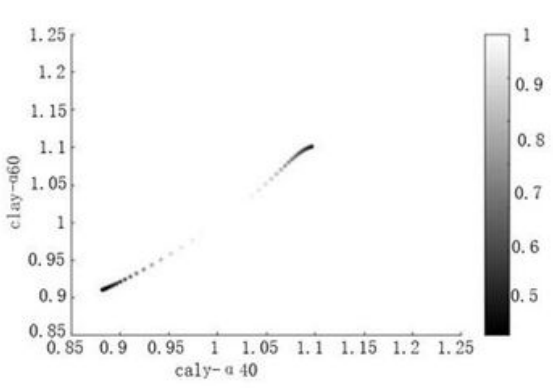

$20-40 \mathrm{~cm}$ and $40-60 \mathrm{~cm}$

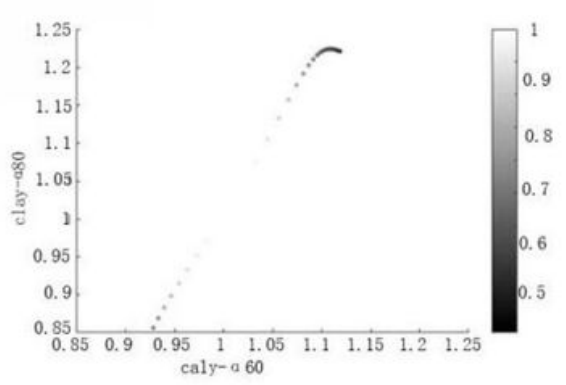

$40-60 \mathrm{~cm}$ and $60-80 \mathrm{~cm}$

b. Joint multi-fractal spectrum projection grayscale of clay content

\section{Figure 5}

Joint multi-fractal spectra and projection grayscale of clay content in SUP. 


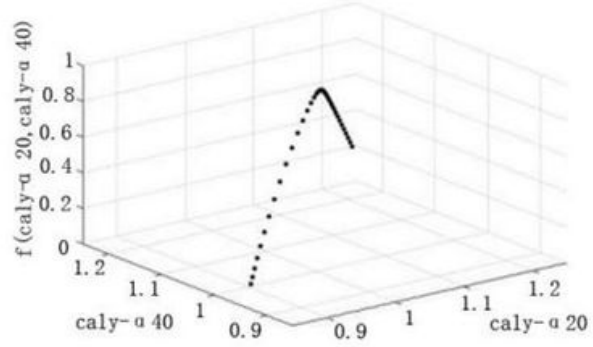

$0-20 \mathrm{~cm}$ and $20-40 \mathrm{~cm}$

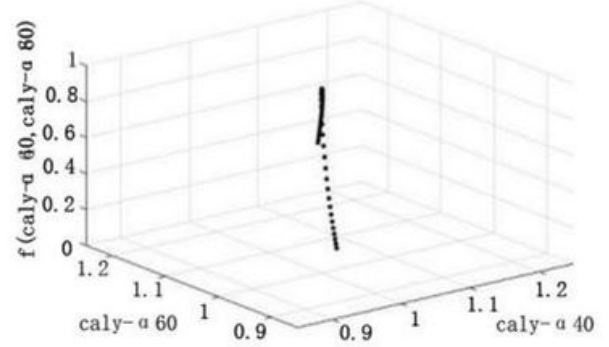

$20-40 \mathrm{~cm}$ and $40-60 \mathrm{~cm}$

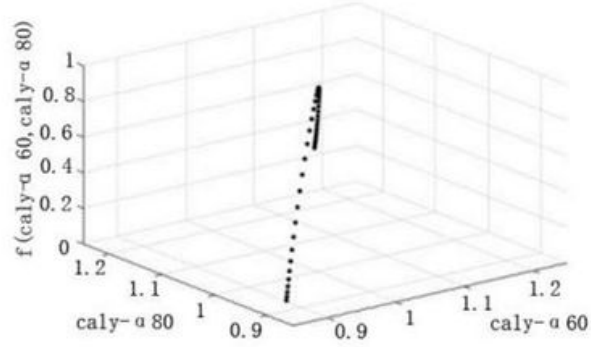

$40-60 \mathrm{~cm}$ and $60-80 \mathrm{~cm}$

a. Joint multi-fractal spectra of clay content

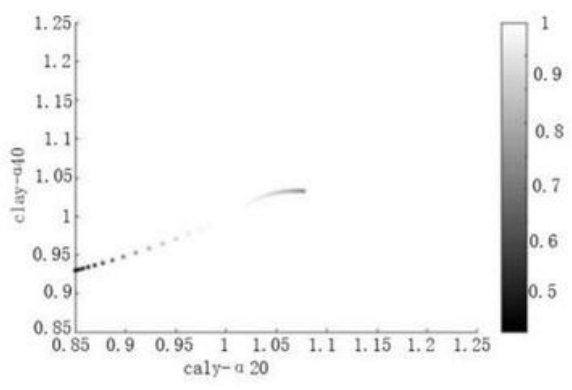

$0-20 \mathrm{~cm}$ and $20-40 \mathrm{~cm}$

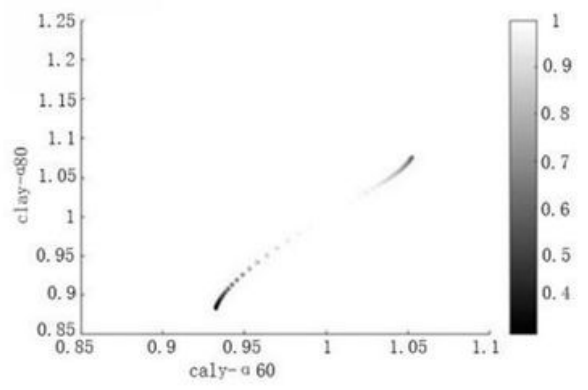

$20-40 \mathrm{~cm}$ and $40-60 \mathrm{~cm}$

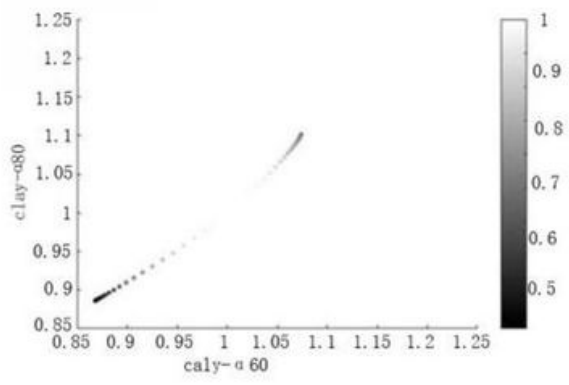

$40-60 \mathrm{~cm}$ and $60-80 \mathrm{~cm}$

b. Joint multi-fractal spectrum projection grayscale of clay content

Figure 6

Joint multi-fractal spectra and projection grayscale of clay content in RCP. 


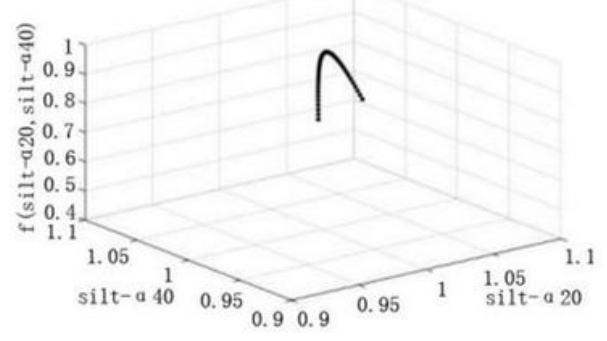

$0-20 \mathrm{~cm}$ and $20-40 \mathrm{~cm}$

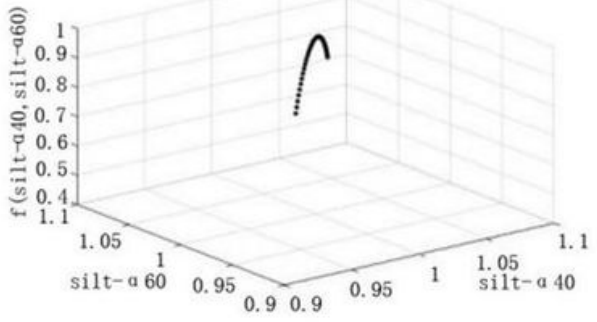

$20-40 \mathrm{~cm}$ and $40-60 \mathrm{~cm}$

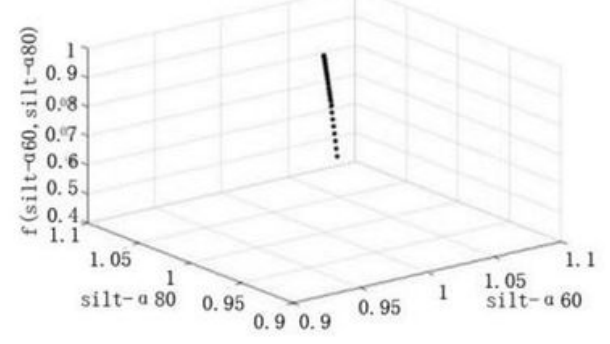

$40-60 \mathrm{~cm}$ and $60-80 \mathrm{~cm}$

a. Joint multi-fractal spectra of silt content

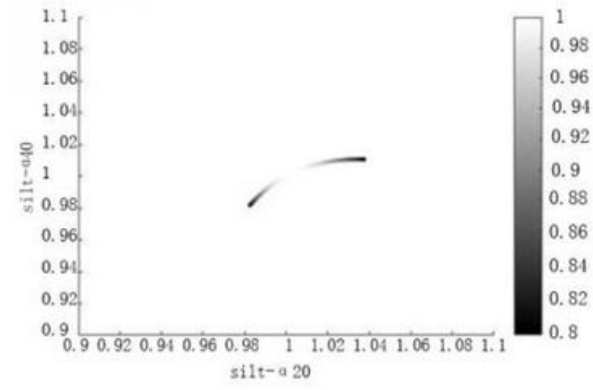

$0-20 \mathrm{~cm}$ and $20-40 \mathrm{~cm}$

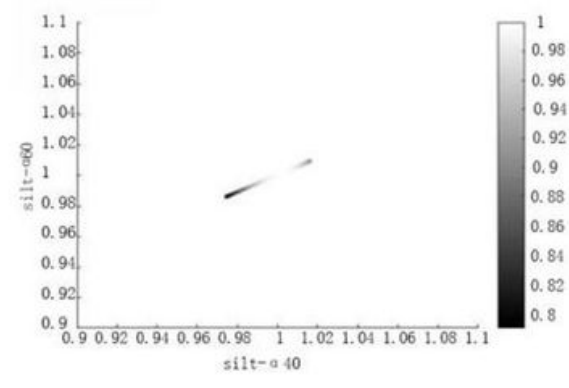

$20-40 \mathrm{~cm}$ and $40-60 \mathrm{~cm}$

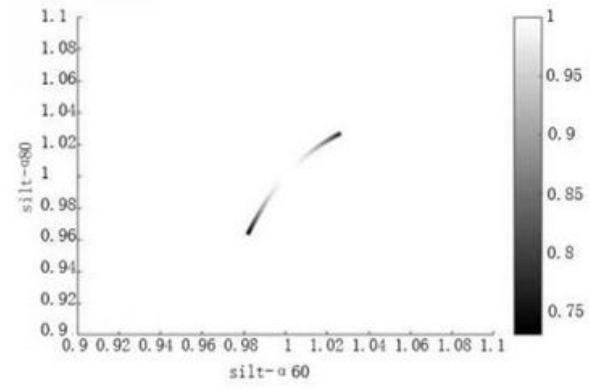

$40-60 \mathrm{~cm}$ and $60-80 \mathrm{~cm}$

b. Joint multi-fractal spectrum projection grayscale of silt content

Figure 7

Joint multi-fractal spectra and projection grayscale of silt content in UMP. 


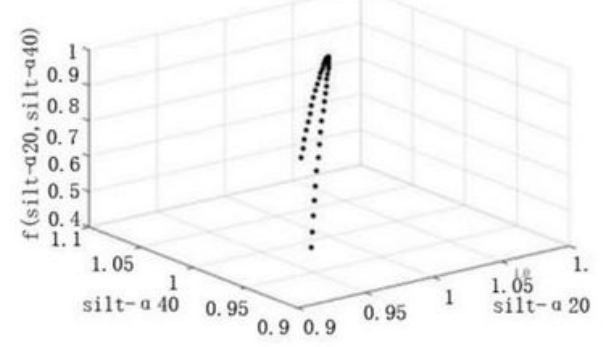

$0-20 \mathrm{~cm}$ and $20-40 \mathrm{~cm}$

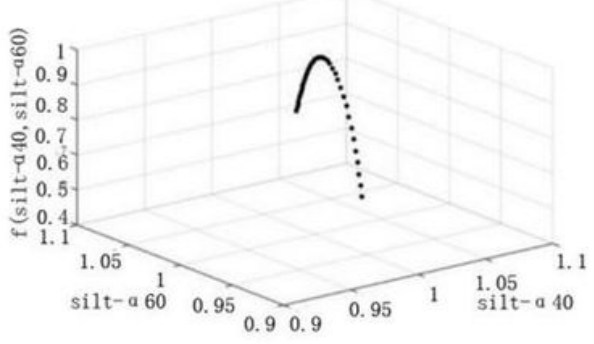

$20-40 \mathrm{~cm}$ and $40-60 \mathrm{~cm}$

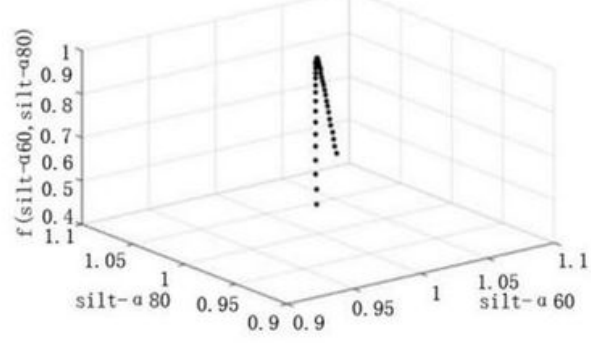

$40-60 \mathrm{~cm}$ and $60-80 \mathrm{~cm}$

a. Joint multi-fractal spectra of silt content

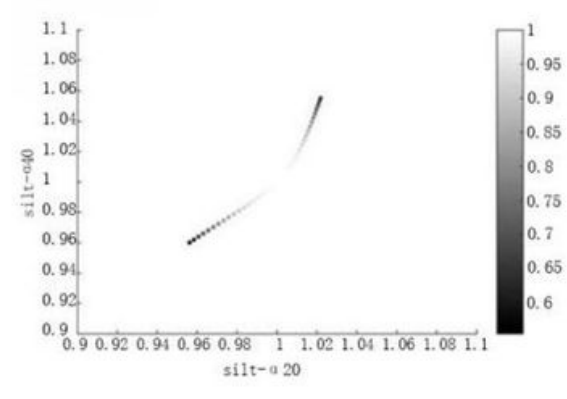

$0-20 \mathrm{~cm}$ and $20-40 \mathrm{~cm}$

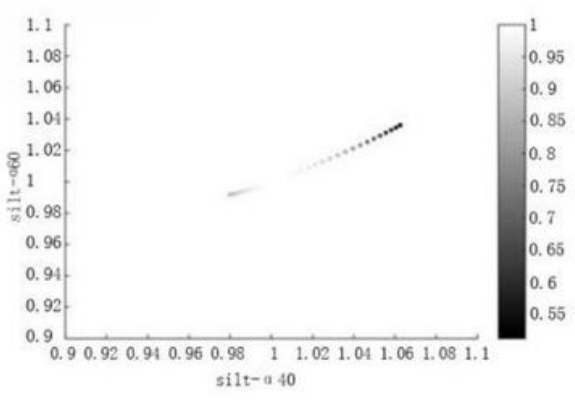

$20-40 \mathrm{~cm}$ and $40-60 \mathrm{~cm}$

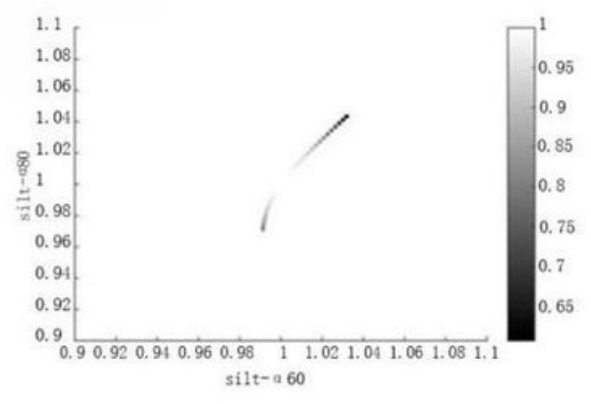

$40-60 \mathrm{~cm}$ and $60-80 \mathrm{~cm}$

b. Joint multi-fractal spectrum projection grayscale of silt content

Figure 8

Joint multi-fractal spectra and projection grayscale of silt content in SUP. 


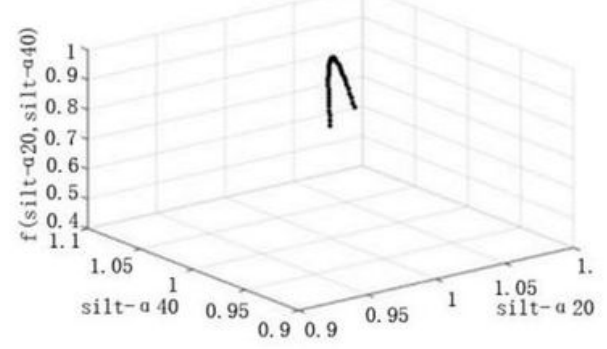

$0-20 \mathrm{~cm}$ and $20-40 \mathrm{~cm}$

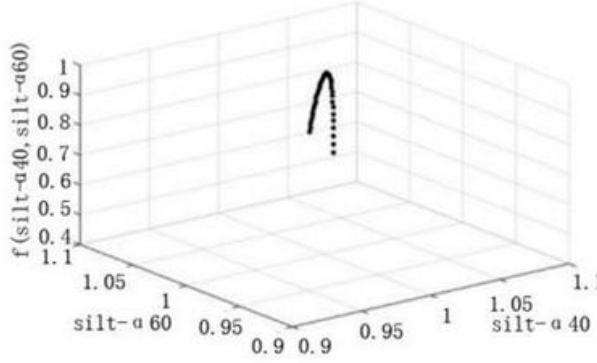

$20-40 \mathrm{~cm}$ and $40-60 \mathrm{~cm}$

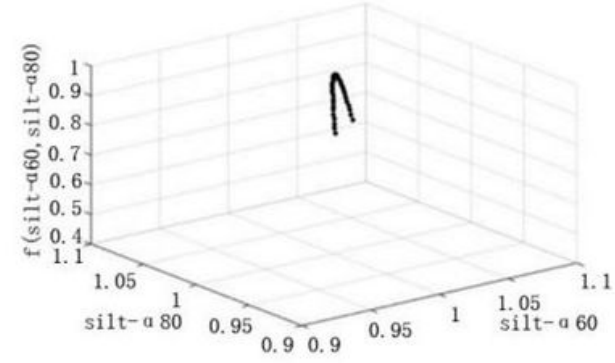

$40-60 \mathrm{~cm}$ and $60-80 \mathrm{~cm}$

a. Joint multi-fractal spectra of silt content

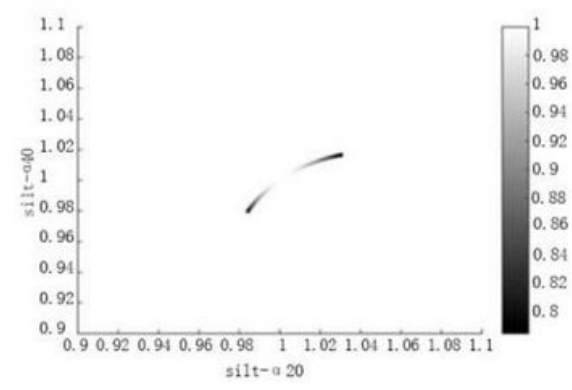

$0-20 \mathrm{~cm}$ and $20-40 \mathrm{~cm}$

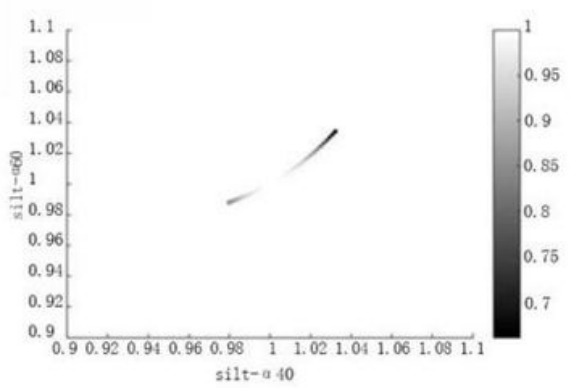

$20-40 \mathrm{~cm}$ and $40-60 \mathrm{~cm}$

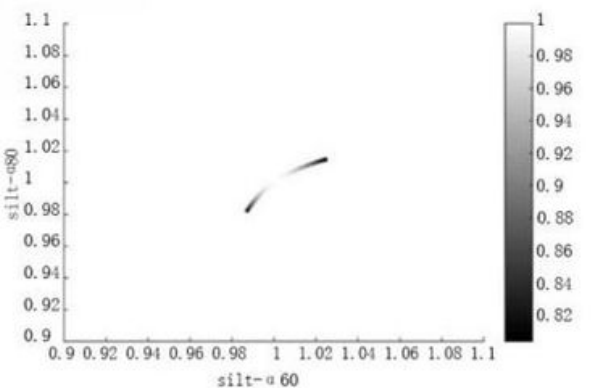

$40-60 \mathrm{~cm}$ and $60-80 \mathrm{~cm}$

b. Joint multi-fractal spectrum projection grayscale of silt content

Figure 9

Joint multi-fractal spectra and projection grayscale of silt content in RCP. 


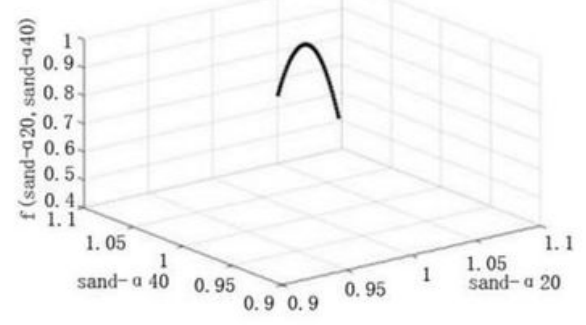

$0-20 \mathrm{~cm}$ and $20-40 \mathrm{~cm}$

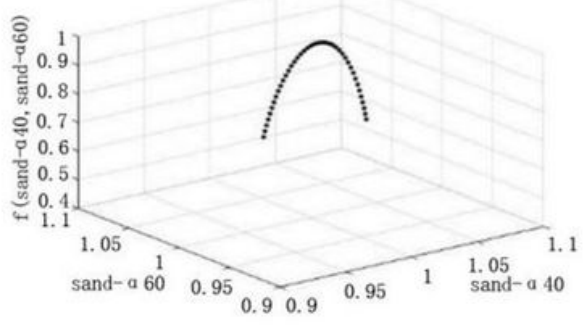

$20-40 \mathrm{~cm}$ and $40-60 \mathrm{~cm}$

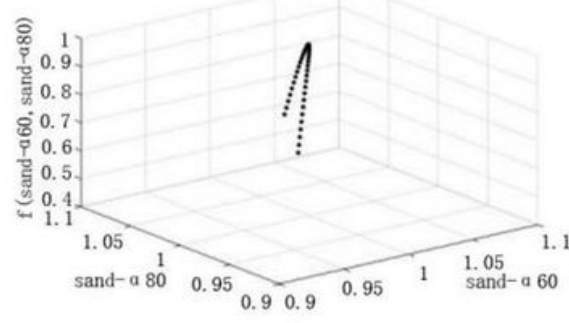

$40-60 \mathrm{~cm}$ and $60-80 \mathrm{~cm}$

a. Joint multi-fractal spectra of sand content

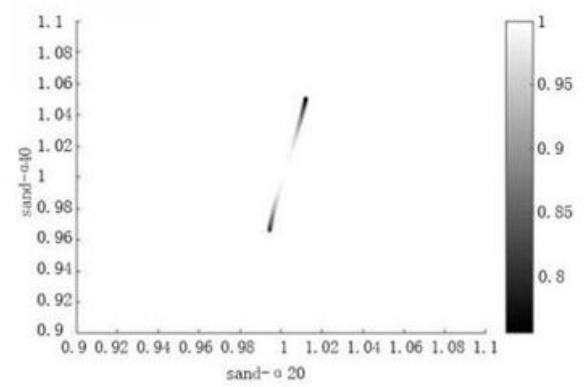

$0-20 \mathrm{~cm}$ and $20-40 \mathrm{~cm}$

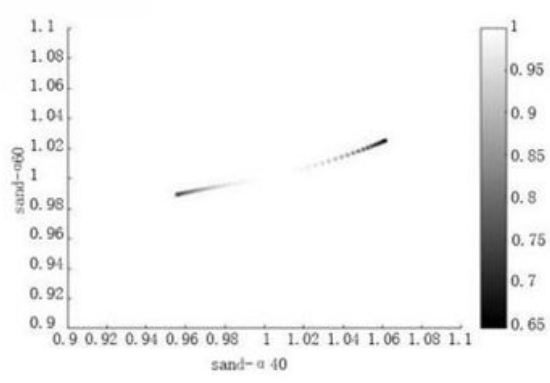

$20-40 \mathrm{~cm}$ and $40-60 \mathrm{~cm}$

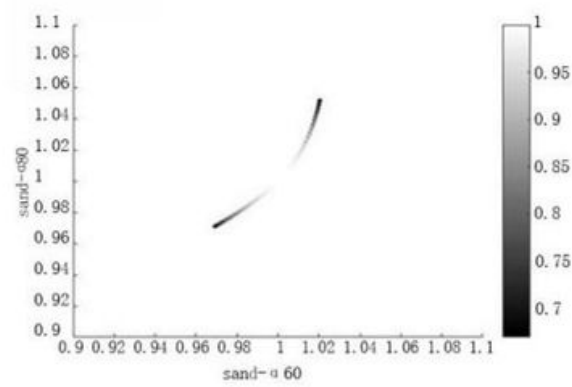

$40-60 \mathrm{~cm}$ and $60-80 \mathrm{~cm}$

b. Joint multi-fractal spectrum projection grayscale of sand content

\section{Figure 10}

Joint multi-fractal spectra and projection grayscale of sand content in UMP. 


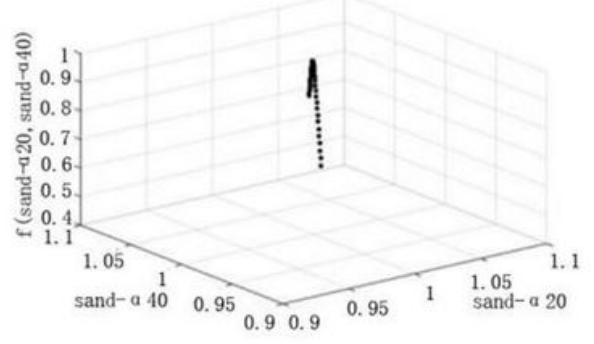

$0-20 \mathrm{~cm}$ and $20-40 \mathrm{~cm}$

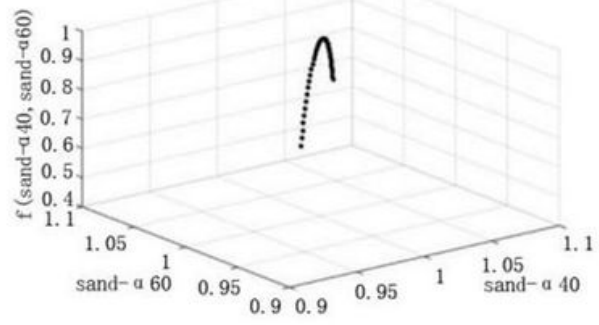

$20-40 \mathrm{~cm}$ and $40-60 \mathrm{~cm}$

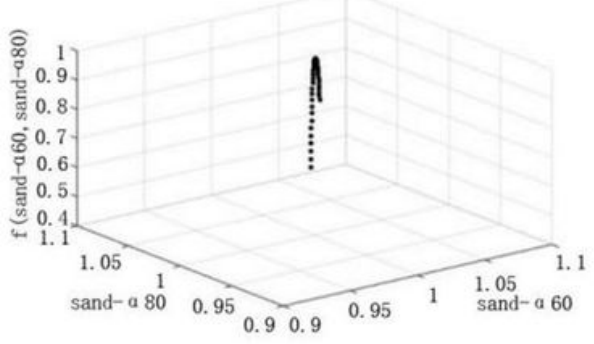

$40-60 \mathrm{~cm}$ and $60-80 \mathrm{~cm}$

a. Joint multi-fractal spectra of sand content

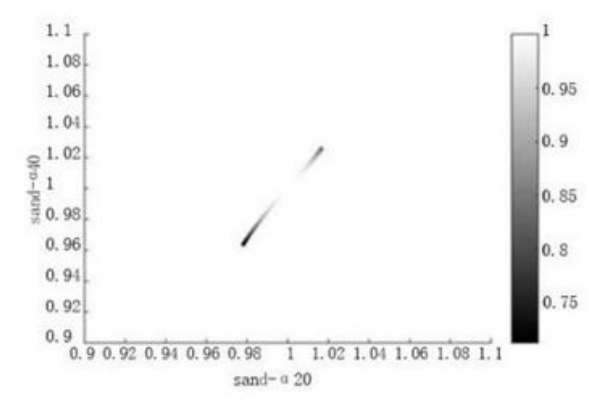

$0-20 \mathrm{~cm}$ and $20-40 \mathrm{~cm}$

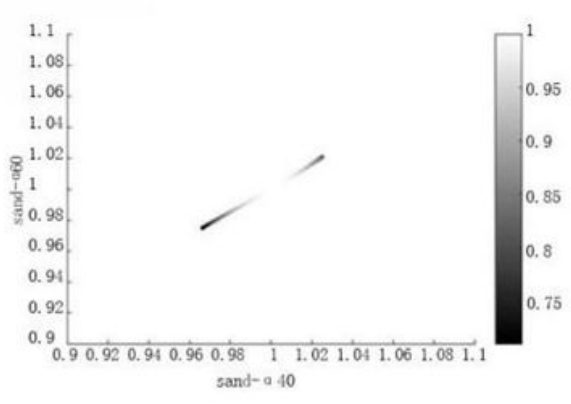

$20-40 \mathrm{~cm}$ and $40-60 \mathrm{~cm}$

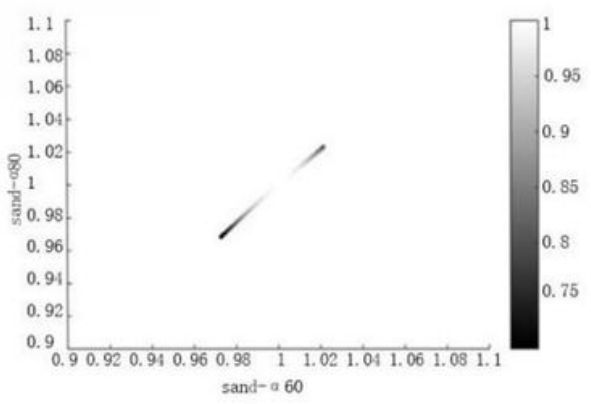

$40-60 \mathrm{~cm}$ and $60-80 \mathrm{~cm}$

b. Joint multi-fractal spectrum projection grayscale of sand content

\section{Figure 11}

Joint multi-fractal spectra and projection grayscale of sand content in SUP. 


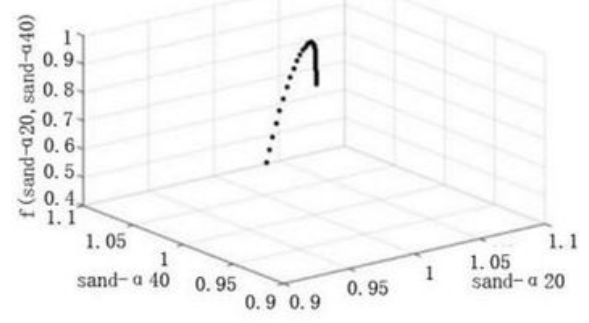

$0-20 \mathrm{~cm}$ and $20-40 \mathrm{~cm}$

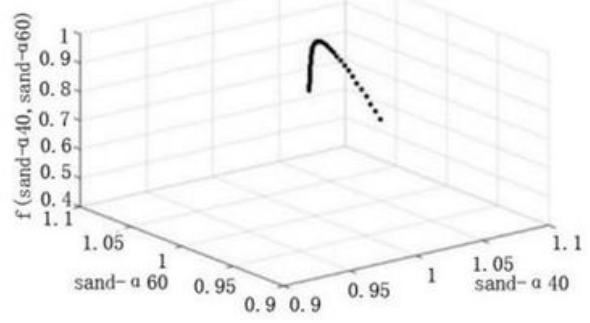

$20-40 \mathrm{~cm}$ and $40-60 \mathrm{~cm}$

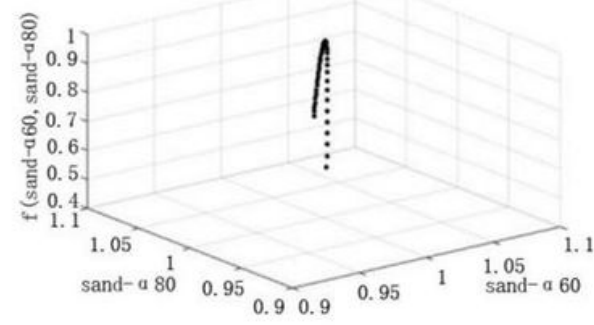

$40-60 \mathrm{~cm}$ and $60-80 \mathrm{~cm}$

a. Joint multi-fractal spectra of sand content

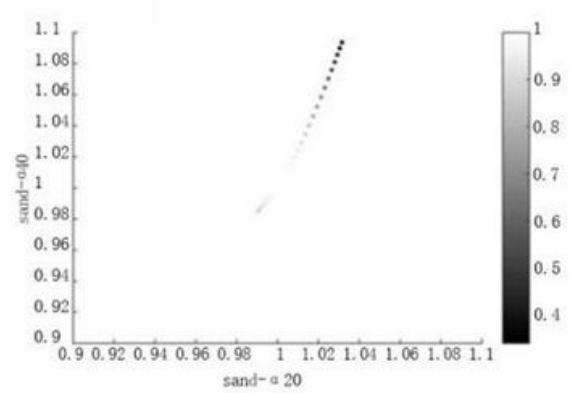

$0-20 \mathrm{~cm}$ and $20-40 \mathrm{~cm}$

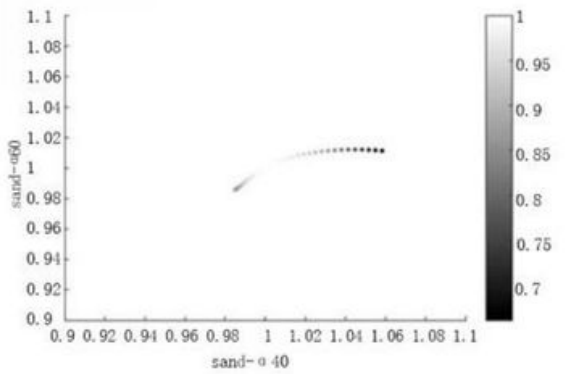

$20-40 \mathrm{~cm}$ and $40-60 \mathrm{~cm}$

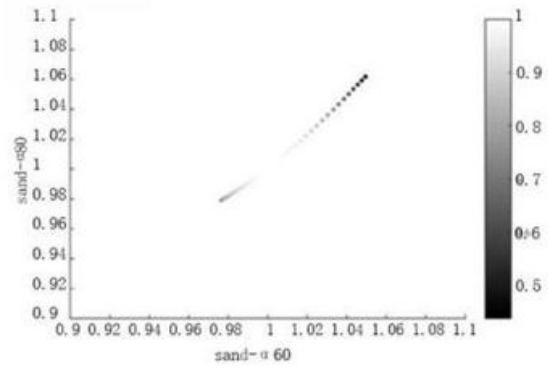

$40-60 \mathrm{~cm}$ and $60-80 \mathrm{~cm}$

b. Joint multi-fractal spectrum projection grayscale of sand content

Figure 12

Joint multi-fractal spectra and projection grayscale of sand content in RCP. 